\title{
A study to evaluate efficacy of Tinospora cordifolia (Guduchi) as analgesic agent using albino wistar rats as an experimental animal model
}

\author{
Purnendu Mandal', Asoke Kumar Das², Ananya Mandal ${ }^{3 *}$, Tuhin Kanti Biswas ${ }^{4}$
}

\begin{abstract}
${ }^{1}$ Department of Pharmacology, Raiganj Government Medical College and Hospital, Raiganj, West Bengal, India
${ }^{2}$ Department of Pharmacology, College of Medicine and Sagore Dutta Hospital, Kolkata, West Bengal, India

${ }^{3}$ Department of Pharmacology, NRS Medical College and Hospital, Kolkata, West Bengal, India

${ }^{4}$ Department of Pharmacology, J.B. Roy State Ayurvedic Medical College and Hospital (Kaya Chikitsa), Kolkata,

West Bengal, India
\end{abstract}

Received: 06 December 2019

Revised: 14 January 2020

Accepted: 16 January 2020

*Correspondence:

Dr. Ananya Mandal,

Email: drananyamandal@gmail.com

Copyright: (C) the author(s), publisher and licensee Medip Academy. This is an open-access article distributed under the terms of the Creative Commons Attribution Non-Commercial License, which permits unrestricted non-commercial use, distribution, and reproduction in any medium, provided the original work is properly cited.

\begin{abstract}
Background: Pain is a very well-known symptom of many diseases and analgesics are used to relieve pain. The main problem with these drugs remains that of side effects. Herbal medicines are better in view of their cultural acceptability, better compatibility with human body systems and lesser incidence of side effects. Extract of Tinospora cordifolia (Guduchi) plant have been traditionally used to treat pain in traditional medicine.

Methods: Commercially available preparation of $T$. cordifolia plant has been used as test drug (aqueous extract). Healthy albino rats of either sex, weighing between 140-200 g were selected for the study, divided into 4 groups of 6 each (control, standard, $100 \mathrm{mg} / \mathrm{kg}, 300 \mathrm{mg} / \mathrm{kg}$ ). Central analgesic activity was assessed by tail flick model (morphine as standard drug I.P). Acetic acid $1 \% 10 \mathrm{ml} / \mathrm{kg}$ aqueous solution I.P. was used for abdominal writhing model. Diclofenac $150 \mathrm{mg} / \mathrm{kg}$ oral as standard drug for assessment of peripheral analgesic activity. Results were analysed using SPSS version 16 and Microsoft office excel 2007.

Results: $T$. cordifolia extract significantly increased the tail flick latency time (sec) (mean tail flick latency control, T100, T300 6.833 $\pm 0.25 \mathrm{sec}, 8.65 \pm 017 \mathrm{sec}, 10.01 \pm 0.14$ respectively) (p value control vs T100, T300 at $90 \mathrm{~min}, 120$ min, 0.0573, 0.0198, 0.0198 in between group) and decreased number of abdominal writhing in comparison with the control group ( $\mathrm{p}$ value $<0.0001$ ).

Conclusions: Extract of $T$. cordifolia was found to possess analgesic activity and also exhibited dose and time dependant increase involving central and peripheral mechanisms. The analgesic activity of T. cordifolia found to be comparable to standard drug used.
\end{abstract}

Keywords: Analgesic, T. cordifolia, Abdominal writhing, Tail flick

\section{INTRODUCTION}

Herbal medicines are better in view of their cultural acceptability, better compatibility with human body systems and lesser incidence of side effects. Presently about 70 to $80 \%$ of the world population are relying solely on herbal medicine, mainly in the developing countries. ${ }^{1}$

In India herbal extracts are being used for treatment of diseases for more than 5000 years. $^{2}$ Natural products are accepted to be important sources of new chemical 
substances which have potential therapeutic effects. Medicinal plants, one of the important sources, are extensively investigated both in vitro and in vivo for their potential therapeutic effects. Most people living in developing countries especially in rural areas are almost completely dependent on traditional medicines for their primary health care needs. Higher plants are known to be the main source of such drugs. ${ }^{3}$ In India a sizeable portion of the rural population have no access to modern medicine, it is also time consuming, expensive and inconvenient. ${ }^{4}$ Pain is an unpleasant sensory and emotional experience associated with actual or potential tissue damage. ${ }^{5}$ By acting in the central nervous system (CNS) or on the peripheral pain mechanism, analgesic compounds selectively relieve pain without significant alteration of consciousness. Usually analgesics are prescribed when the noxious stimulus cannot be removed or as adjuvant to more etiological approach to pain. ${ }^{6}$ Pain is an unpleasant sensation but a protective mechanism of our body and is the most common symptom for bringing a patient to the doctor. All the currently available analgesic drugs such as nonsteroidal anti-inflammatory drugs (NSAIDs) and opioid analgesics are subject to their own side effects such as gastric erosions with NSAIDs and tolerance and dependence with opioid analgesics.

T. cordifolia can be an alternative to NSAIDS and opioids as analgesic, so we planned our study to assess Analgesic activity of $T$. cordifolia by using standard animal models for both central and peripheral pain.

\section{METHODS}

Type of study: This was an experimental study.

Study setting: The study was done at Department of Pharmacology, BSMC (Gobindanagar, Campus of BSMC).

Study period: The study was from February 2017 to May 2017.

\section{Study population}

Young, healthy, active Albino Wistar rats (140-200 g) of both sexes selected for the present study. Animals procured in phases for each experiment from registered animal supplier (Ghosh Scientific, Kolkata 700054). These animals were housed in the Central Animal House of the Department of Pharmacology, Bankura Sammilani Medical College, Bankura, and were exposed to natural temperature and humidity.

The animals once selected for the study were separated in cages and were given food and water ad libitum. The animals were kept at ambient temperature of $22 \pm 1^{\circ} \mathrm{C}, 12$ $\mathrm{hr}$ light and dark cycle allowed. Animals were allowed free intermingling prior to experimental study.
During the experiment the animals were kept in a fasting state and after the experiments they were rehabilitated in the same animal house and not used subsequently all procedures tried to do in less painful ways.

\section{Ethical considerations}

All experiments were conducted with due care in accordance to Committee for the purpose of Control and Supervision of Experiments on Animals (CPCSEA) and good laboratory practice rules and guidelines. ${ }^{7,8}$ The study was approved by the Institutional Animal Ethical Committee (IAEC) of BSMC, Bankura [BSMC/Aca/3869]. No animals were sacrificed at the end of the study. Animals were acclimatized to laboratory conditions for 14 days prior to taking them for experimentation. ${ }^{9}$

\section{Test drugs and chemicals}

Morphine (5 mg/kg i.p.) used as standard drug for evaluation of central analgesic effect, diclofenac (150 $\mathrm{mg} / \mathrm{kg}$ oral) used for evaluation of peripheral analgesic activity. T. cordifolia extract procured commercially.

\section{Dose calculation}

Dose calculation done using standard Table of Paget and Barnes, drugs administered by gavage feeding and intra peritoneal route as per animal model. ${ }^{10-13}$

\section{Experimental model}

Central analgesic activity assessed by Tail flick test in rats, second widely used animal model for the evaluation of analgesic activity in either rat or mice. ${ }^{14}$ Acetic acid $(0.1 \mathrm{ml}$ of a $1.0 \%$ solution, i.p.) induced abdominal Writhing used for evaluation of peripheral analgesic activity. ${ }^{15}$ Central analgesic activity assessment was done by tail flick analgesiometer (IMCORP, Ambala, India) and for peripheral analgesic activity acetic acid (Fischer inorganic and Aromatic Ltd, Chennai, India ) was used. Scheme of study depicted in Figure 1 and 2.

\section{Acute toxicity study}

Acute toxicity study was carried out according to Organisation for Economic Co-operation and Development (OECD) guideline 423. ${ }^{16}$ Animals of both sexes were selected by random sampling method dividing into 5 groups $(n=3)$ a single oral dose. aqueous extract of T. cordifolia starting from $100 \mathrm{mg} / \mathrm{kg}$ and progressively moving from $200 \mathrm{mg} / \mathrm{kg}, 400 \mathrm{mg} / \mathrm{kg}, 600 \mathrm{mg} / \mathrm{kg}$ up to $800 \mathrm{mg} / \mathrm{kg}$ was administered. The animal groups were observed for appearance of toxic symptoms including behavioural changes, locomotion, muscle spasm, loss of righting reflex, tremor, convulsions and mortality for 24 hours and after that observed for 14 days. 


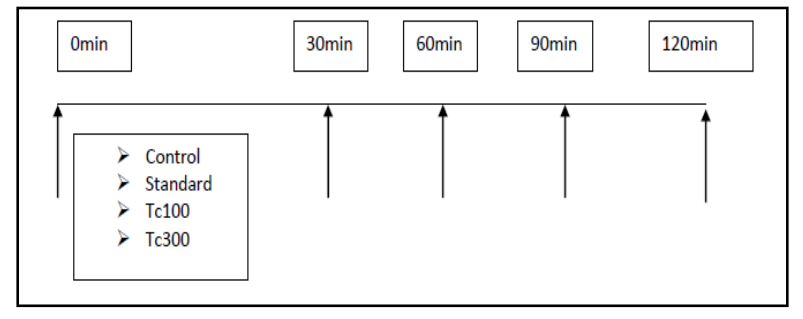

Figure 1: Schematic plan for tail flick test.

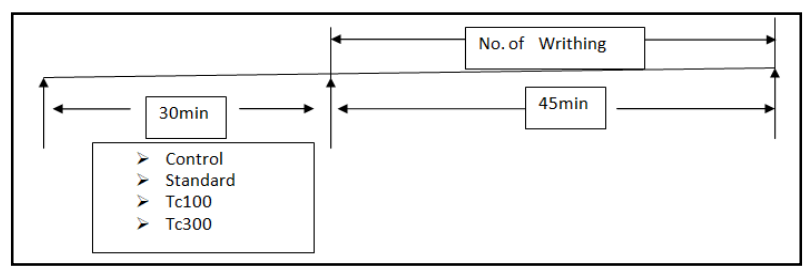

Figure 2: Schematic plan of acetic acid $(1 \%, 10 \mathrm{ml} / \mathrm{Kg})$ induced abdominal writhing.

Sample size calculation done using G*POWER version 3.1.9.2 and data analysed using SPSS Version 16 and Microsoft Excel 2007. Statistically significant differences between groups and within groups were calculated by the application of analysis of variance followed by multiple comparison tests.

\section{RESULTS}

Figure 3 shows change of mean latency time in all groups with time. The mean latency time has been increased in both T100 and T300 group.

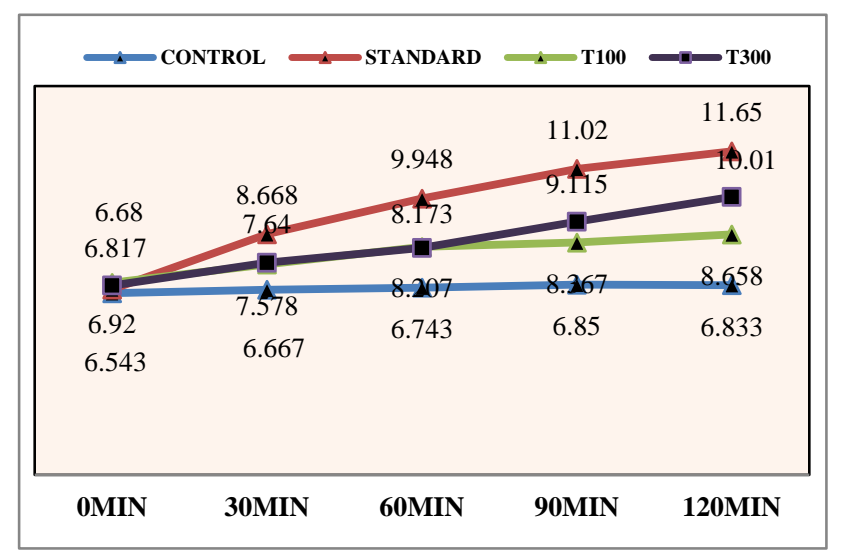

Figure 3: Tail flick latency vs time.

In between groups analysis (Kruskall Wallis followed by Dunn multiple comparison) revealed there is significant difference present between control, standard, T100 group but no significant difference between T300 and Standard at $90 \mathrm{~min}(\mathrm{p}=0.54)$. Within group (Friedman ANOVA followed by Dunn post hoc test) revealed there is significant difference present between both T100 and T300 group at $60 \mathrm{~min}, 90 \mathrm{~min}$ and $120 \mathrm{~min}$ ( $\mathrm{p}$ value for T100 0.0187*, $0.0248^{*},<0.0001^{* * * *}$ respectively, p value for $\mathrm{T} 300$ was $0.0011^{*}, 0.0041^{*},<0.0001 * * * *$ respectively) (Table 1 and 2).

There is significant difference present in between groups. (control, standard, T100, T300) depicted in Table 3. Notably, no statistical difference present between standard vs T300 ( $\mathrm{p}$ value was >0.9999). Figure 4 shows the change in number of abdominal writhing, standard group having minimum number of abdominal writhing $12.5 \pm 1.72$ followed by T300 group $15 \pm 2.09$ and T100

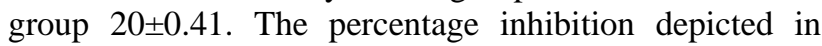
Figure 5, revealed the percentage inhibition being $45.24 \%$ in standard, $12.39 \%$ in T100 and $34.29 \%$ in T300 group.

Table 1: In between group analysis ( $\mathrm{p}$ value-Kruskal Wallis).

\begin{tabular}{|lll|}
\hline 60 $\min$ & 90 $\mathbf{m i n}$ & $\mathbf{1 2 0}$ min \\
\hline S-T100 & S-T100 & C-T300 \\
$0.0416^{*}$ & $0.0274^{*}$ & $0.0198^{*}$ \\
\hline S-T300 & S-T300 & S-T100 \\
$0.0189^{*}$ & 0.54 & $0.0198^{*}$ \\
\hline & & S-T300 \\
& & 0.84 \\
\hline
\end{tabular}

Table 2: Within group analysis (p value -Friedman ANOVA)

\begin{tabular}{|llll|}
\hline T100 & 60 min & 90 min & 120 min \\
\hline T300 & $0.0011^{*}$ & $0.0248^{*}$ & $<0.0001^{* * * *}$ \\
\hline
\end{tabular}

Table 3: Significant difference between groups in number of abdominal writhing.

\begin{tabular}{|l|l|}
\hline Dunn's multiple comparisons test & P value \\
\hline Control vs. standard & $0.0004^{* * *}$ \\
\hline Control vs. T100 & $>0.9999$ \\
\hline Control vs. T300 & $0.0179^{*}$ \\
\hline Standard vs. T100 & $0.0233^{*}$ \\
\hline Standard vs. T300 & $>0.9999$ \\
\hline T100 vs. T300 & 0.3915 \\
\hline
\end{tabular}

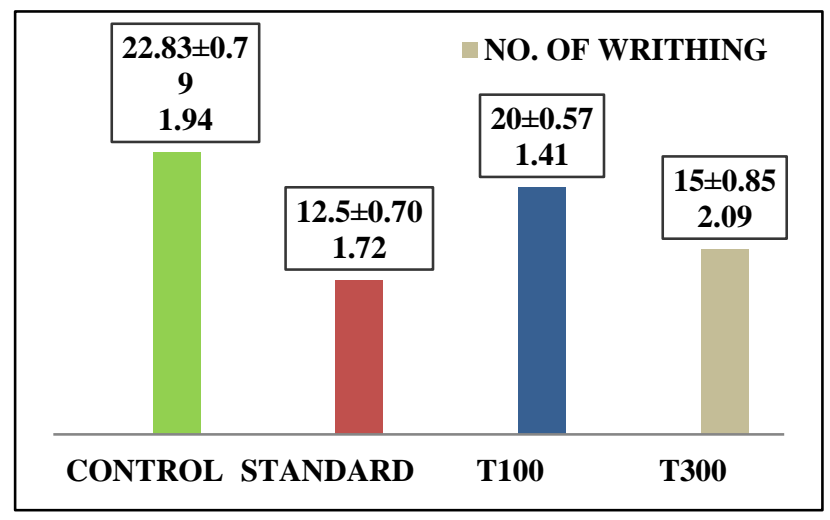

Figure 4: Abdominal writhing (number) in all four groups. 


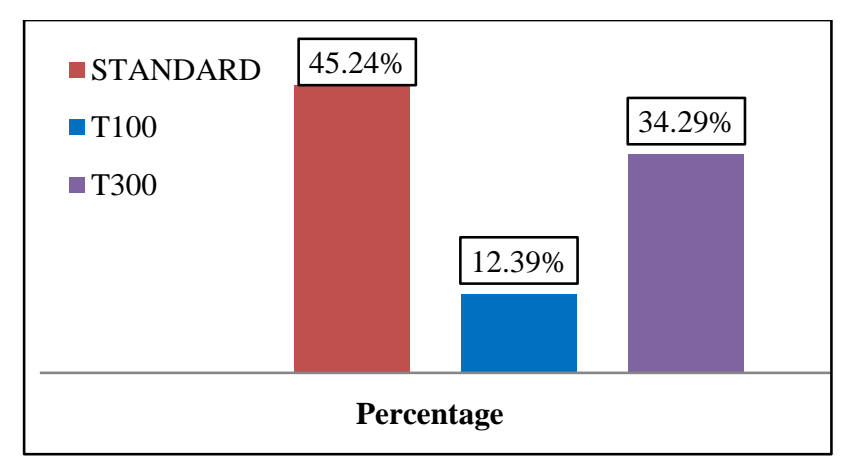

Figure 5: Percentage inhibition of abdominal writhing in comparison to control group.

\section{DISCUSSION}

In analgesic activity test of the $T$. cordifolia (Guduchi), experimental animal models included the tail flick test and acetic acid induced abdominal writhing tests. Tail flick test revealed there is significant difference in mean latency of tail flick T100 AND T300 group in comparison to control Group at $90 \mathrm{~min}$ and $120 \mathrm{~min}$ observations (p value was $0.0573,0.0198$, and 0.0198 respectively) in between group analysis. Further there is significant difference between mean latency to tail flick of standard and T100 at $90 \mathrm{~min}, 120 \mathrm{~min}$ and standard vs T300 at 60 min. But there is no statistically significant difference between standard and $\mathrm{T} 300$ at $90 \mathrm{~min}$ and $120 \mathrm{~min}$. Within group analysis revealed there is gradual increase in mean latency of tail flick with time from baseline in all four groups.

Bhomik et al has shown the group of rats receiving $T$. cordifolia extract showed statistically significant difference with the control group at 60 minutes $(\mathrm{p}<0.01)$, 90 minutes $(\mathrm{p}<0.01)$ and 120 minutes $(\mathrm{p}<0.05)$ in hot plate method and produced statistically significant decrease in writhes count when compared with the control group $(\mathrm{p}<0.001)$. These results show that this extract possess a significant analgesic activity in Hot Plate Test. ${ }^{17}$ Hussain et al showed increase in mean latency time of tail flick (sec) in extract treated group in comparison with control group using mice as experimental animal and tramadol as standard drug in both tail flick and hot plate test. ${ }^{18}$ Siddhalingappa et al also found out that $T$. cordifolia aqueous extract significant increase in the reaction time (pain threshold) in doses of $100 \mathrm{mg} / \mathrm{kg}, 200$ $\mathrm{mg} / \mathrm{kg} .{ }^{19}$

The evaluation of number of writhing revealed that both $100 \mathrm{mg} / \mathrm{kg}$ and $300 \mathrm{mg} / \mathrm{kg}$ doses of test drug reduces number of abdominal writhing significantly in comparison to control group. ( $\mathrm{p}$ value $0.0314,<0.0001$ respectively). T300 group showed no significant difference in comparison to standard group in assessment of reduction of number of abdominal writhing ( $p$ value 0.0917). There is significant difference present between standard vs T100 group in assessing reduction of number of abdominal writhing ( $p$ value $<0.0001$ ). Hussain et al showed $T$. cordifolia significantly inhibited the number of writhes in dose dependant manner. Maximum inhibition in T300 group with no difference with standard drug when diclofenac sodium used as standard drug using mice as experimental animal ( $\mathrm{p}$ value $<0.05$ ). ${ }^{18}$ Bhomik et al has shown administration of this $T$. cordifolia extract orally and pentazocine intraperitoneally significantly reduce writhes counts $(\mathrm{p}<0.001$ and $\mathrm{p}<0.001$ respectively) when compared with the control group in sodium chloride $(\mathrm{NaCl})$ induced abdominal writhing method using rats as experimental animal. ${ }^{17}$

\section{CONCLUSION}

Commercially available extract of $T$. cordifolia "guduchi" was found to possess analgesic activity that might involve central (opioid receptors) as well as peripheral (inhibition of PG synthesis) mechanisms. Though not as efficacious as standard analgesic drugs used, its analgesic comparable to standard drug used. T. cordifolia also showed dose and time dependant increase of analgesic, anti-inflammatory and antipyretic activity.

During course of the experiment no adverse event/ fatalities have occurred and the animals also did not show any post experiment adverse effect in period of 2-week observation. Their eating/social behavior showed no abnormality during this period. Based on these results, it is clearly that the $T$. cordifolia possesses analgesic, antipyretic and anti-inflammatory activities in experimental animal models which support the traditional uses of $T$. cordifolia commonly called as Guduchi in Sanskrit and Giloy in Hindu folklore medicine.

\section{ACKNOWLEDGEMENTS}

We sincerely express our gratitude to Dr. Syed Mohammad Naser, Associate Professor and H.O.D, Department of Pharmacology, BSMC, Bankura, for his valuable advice, constructive criticism and his extensive discussions around my work.

\section{Funding: No funding sources}

Conflict of interest: None declared

Ethical approval: The study was approved by the Institutional Ethics Committee, BSMC/ Aca / 3869

\section{REFERENCES}

1. Ekor M. The growing use of herbal medicines: issues relating to adverse reactions and challenges in monitoring safety. Front Pharmacol. 2014;4:177.

2. Aggarwal B, Prasad S, Reuter S. Identification of Novel Anti-Inflammatory Agents from Ayurvedic Medicine for Prevention of Chronic Diseases: 'Reverse Pharmacology' and 'Bedside to Bench' Approach. Curr Drug Targets. 2011;12:1595-653.

3. Calixto JB. Twenty-five years of research on medicinal plants in Latin America: a personal view. J Ethnopharmacol. 2005;100:131-4. 
4. Ganapati M. Mandatory rural practice proposed in India. BMJ. 1995;311:1186.

5. Loeser JD. The Kyoto protocol of IASP Basic Pain Terminology. Pain. 2008;137:473-77.

6. Dewan SMR, Amin MN, Adnan T. Investigation of analgesic potential and in vitro antioxidant activity of two plants of Asteraceae family growing in Bangladesh. J Pharm Res. 2016;6:599-603.

7. Ministry of Environment, Forest and Climate Change Government of India. Compendium of CPCSEA. New Delhi: CPCSEA; 2018: 60-87.

8. Indian Council of Medical Research, New Delhi. 2008. Available at: https://www.icmr.nic.in/sites/ default/files/guidelines/GCLP.pdf. Accessed on 5 December 2019.

9. Ministry of Environment, Forest and Climate Change Government of India. Compendium of CPCSEA. New Delhi: CPCSEA; 2018: 62.

10. Karnam N. Screening of a novel-substituted furan compound for analgesic activity in mice. Int $\mathrm{J}$ Basic Clin Pharmacol. 2017;5:1759-63.

11. Paget GE. Evaluation of Drug Activities and Pharmacometrics: London NY: Academic Press; 1964.

12. UBC Animal Care Guidelines, SOP: ACC-2012Tech09. Available at: ACC-2012-Tech09 Oral Dosing (Gavage) in the Mouse and Rat) Updated Feb 2015 final_cc, ka.pdf. Accessed on 5th Dec 2019.

13. UBC Animal Care Guidelines. SOP: ACC-2012Tech10. Available at: https://animalcare.ubc.ca/sites/ default/files/documents/TECH\%2010\%20IP\%20Inje ctions \%20in\%20the\%20Mouse\%20and\%20Rat.pdf. Accessed on 5th Dec 2019.
14. Kulkarni S. Handbook of Experimental Pharmacology. 4th edition. New Delhi: Vallabh Publication; 2012.

15. Medhi B, Prakash A. Practical Manual of Experimental and Clinical Pharmacology: Jaypee Brothers Medical Publishers (P) Ltd; 2010: 225-27.

16. OECD guideline for testing of chemicals. Available at: $\quad$ https://ntp.niehs.nih.gov/iccvam/suppdocs/ feddocs/oecd/oecd_g1423.pdf. Accessed on 5th Dec 2019.

17. Goel B, Pathak N, Nim DK, Singh SK, Dixit RK, Chaurasia R. Clinical Evaluation of Analgesic Activity of Guduchi (Tinospora Cordifolia) Using Animal Model. J Clin Diagn Res. 2014;8:1-4.

18. Hussain L, Akash MSH, NUA, Rehman K, Ibrahim M. The Analgesic, Anti-Inflammatory and AntiPyretic Activities of Tinospora cordifolia. Adv Clin Exp Med. 2015; 24:957-64.

19. Siddalingappa CM, RajeshT, Kudagi BL, Krishnakanth K, Sujith TR. Evaluation of analgesic and anti- inflammatory activities of Tinospora cordifolia in rodents. Int $\mathbf{J}$ Basic Med Sci. 2011;2:447.

Cite this article as: Mandal P, Das AK, Mandal A, Biswas TK. A study to evaluate efficacy of Tinospora cordifolia (Guduchi) as analgesic agent using albino wistar rats as an experimental animal model. Int J Basic Clin Pharmacol 2020;9:242-6. 